\title{
Relapsing peritonitis caused by Corynebacterium amycolatum in a patient undergoing continuous ambulatory peritoneal dialysis: a case report
}

\author{
Meliha Cagla Sonmezer1', Günay Tuncer Ertem¹, Meltem Arzu Yetkin'1, Eda Yıldız², Behiç Oral1
}

1. Department of Infectious Diseases and Clinical Microbiology, Ankara Training and Research Hospital, Ankara, Turkey.

2. Department of Microbiology and Clinical Microbiology, Ankara Training and Research Hospital, Ankara, Turkey.

\begin{abstract}
Peritonitis is a common clinical problem in patients treated by peritoneal dialysis. Corynebacterium species are an uncommon cause of continuous ambulatory peritoneal dialysis (CAPD) related peritonitis, and Corynebacterium amycolatum (C. amycolatum) is rarely described in the literature. In the present case, we report relapsing peritonitis caused by $C$. amycolatum in a 55-year-old Turkish woman with normal immune function undergoing CAPD. The pathological diagnosis was nephrotic syndrome. The patient was treated with intraperitoneal (IP) vancomycin. No bacterial growth was detected in conventional culture media, however, bacteria were isolated from the peritoneal fluid culture on second day by BACTEC (Becton Dickinson, USA) automated blood culture system. The organism was identified as C. amycolatum by Gram stain, colony morphology and numerous biochemical tests including API CORYNE kit (bioMerieux, France). To our knowledge, this is the first report of relapsing peritonitis caused by $\mathrm{C}$. amycolatum in a patient undergoing CAPD. This bacterium should be kept in mind as a possible agent in CAPD patients with peritonitis.
\end{abstract}

Key words

Peritoneal dialysis, continuous ambulatory and adverse effects; Peritonitis and microbiology; Corynebacterium

\section{Corresponding Author}

Meliha Cagla Sonmezer

Department of Infectious Diseases and Clinical Microbiology,

Ankara Training and Research Hospital, Ankara, Turkey.

Email: caglasonmezer@hotmail.com 


\section{Introduction}

Peritonitis is a serious complication of CAPD and probably the most common cause of technique failure in CAPD. ${ }^{1-3}$ In the latest recommendations for the management of CAPD-related infections published by the International Society for Peritoneal Dialysis (ISPD) in 2005 two similar conditions, relapsing peritonitis and recurrent peritonitis, are defined. ${ }^{4,5}$ In essence, peritonitis that is treated with appropriate antibiotic therapy, and appears to resolve but recurs with the same organism, or as sterile peritonitis within 4 weeks (relapsing peritonitis) is different from an episode of peritonitis that occurs within 4 weeks of a prior episode, but with a different organism (recurrent peritonitis). ${ }^{5}$ Coryneform bacteria are commensals colonizing the skin and mucous membranes of humans and other animals. They are isolated frequently in clinical specimens, and are commonly considered as contaminants without clinical significance. ${ }^{2}$ Infections due to $C$. amycolatum are rare. Only a single case of recurrent peritonitis caused by this organism has so far been reported. ${ }^{3}$ Here we report the first case of relapsing peritonitis due to $C$. amycolatum in a woman undergoing CAPD.

\section{Case Report}

A 55-year-old Turkish woman who had been receiving CAPD therapy for approximately 2 years because of end-stage renal disease due to nephrotic syndrome presented with abdominal pain, fever nausea, vomiting, and cloudy dialysate for 2 days. She had had one episode of peritonitis two years previously. The tunnel and exit sites of the CAPD catheter were found to be normal. On admission, her temperature was $37.9^{\circ} \mathrm{C}$, blood pressure $180 / 80 \mathrm{mmHg}$, pulse rate 110 beats/min, and respiratory rate $22 /$ min. Noteworthy findings on physical examination included abdominal tenderness and pretibial oedema. The white blood cell (WBC) count of the peritoneal effluent was $750 / \mathrm{mm}^{3}$, with neutrophils predominantly. Gram stain of the peritoneal fluid did not show any micro-organisms. In the complete blood count, the WBC count, platelet count, and haemoglobin values were $21,200 / \mathrm{mm} 3$, $246,000 / \mathrm{mm} 3$, and $8.2 \mathrm{~g} / \mathrm{dL}$, respectively. Biochemical analysis showed blood urea nitrogen (BUN) of $110 \mathrm{mg} /$ $\mathrm{dL}$ and creatinine level of $11 \mathrm{mg} / \mathrm{dL}$; albumin level was $2.5 \mathrm{~g} / \mathrm{dL}$ and C-reactive protein was $121 \mathrm{mg} / \mathrm{dL}$. After peritoneal fluid and blood cultures were taken she was empirically given an antibiotic regimen consisting of IP cephazolin and gentamicin. No bacterial growth was detected in conventional culture media, however, bacteria were isolated from the peritoneal fluid culture on the second day by BACTEC (Becton Dickinson, USA) automated blood culture system. Gram staining of the positive bottle revealed gram-positive bacilli. The strain was identified as C. amycolatum by Gram stain, colony morphology and biochemical tests including API CORYNE kit (BioMérieux, France). On the basis of these culture results, the initial regimen was changed to vancomycin $15 \mathrm{mg} / \mathrm{kg} / 5$ days IP. During her hospital stay, the patient's complaints and physical findings gradually lessened. Peritoneal effluent cell counts also decreased to $10 \mathrm{WBCs} / \mathrm{mm}^{3}$. Therapy was continued for 14 days and she was discharged. The peritoneal catheter was not removed. Five days later however, at the first follow-up visit, the peritoneal dialysate was again turbid and the patient presented the same clinical findings and cell count revealed the presence of 300 leucocytes $/ \mathrm{mm}^{3}$. C. amycolatum was isolated again from the peritoneal fluid culture on third day by Bactec (Becton Dickinson, USA) automated blood culture system. At this time IP and intravenous vancomycin was administered, subsequent cultures were negative and the patient has remained in good clinical condition since then.

\section{Discussion}

Corynebacterium is a genus of gram-positive, facultatively anaerobic, non-motile, irregularly shaped rods that comprise part of the normal skin flora. They live in dynamic equilibrium with other resident gram-positive organisms such as Staphylococcus and Micrococcus spp. ${ }^{6}$ Peritonitis is a serious complication of PD that causes substantial morbidity and mortality. The most recent update of the International Society of PD (ISPD) guidelines for PD-related infections, peritonitis occurring within 4 weeks of a prior episode was defined separately as either relapsed (if the dialysate culture yielded the same organism or was sterile) or recurrent peritonitis (if the dialysate culture yielded a organism different from that of the original episode). Peritonitis episodes occurring more than 30 days after a prior episode are considered to be episodes distinct from relapsed and recurrent peritonitis. Such episodes have been referred to as repeated peritonitis if the same organism is isolated from peritoneal 
dialysate. ${ }^{4,5,7}$ To our knowledge, a case of relapsing CAPD peritonitis caused C. amycolatum has not been reported previously. A similar patient who had CAPD peritonitis due to same organism but recurrent peritonitis is reported in the Medline database. ${ }^{8} \mathrm{C}$. amycolatum is an uncommon but significant cause of PD-associated peritonitis. Complete cure with antibiotics alone is possible in the majority of patients, and rates of adverse outcomes are comparable to those seen with peritonitis due to other organisms. Use of vancomycin rather than cephazolin as empiric therapy does not change outcomes, and a 2-week course of antibiotic therapy appears sufficient. ${ }^{9}$

In conclusion, in patients undergoing CAPD, rare pathogens should be considered in case of peritonitis and peritoneal fluid samples should be examined.

\section{References}

1. Piraino B. Peritonitis as a complication of peritoneal dialysis. J Am Soc Nephrol 1998; 9: 1956- 1964.

2. Oreopoulos DG, Tzamaloukas AH. Peritoneal dialysis in the next millennium. Adv Ren Replace Ther 2000; 7: 338-346. http://dx.doi.org/10.1053/jarr.2000.18039

3. Szeto CC, Wong TY, Leung CB, et al. Importance of dialysis adequacy in mortality and morbidity of Chinese CAPD patients. Kidney Int 2000; 58: 400-407. http://dx.doi. org/10.1046/j.1523-1755.2000.00179.x

4. Piraino B, Bailie GR, Bernardini J, et al. Peritoneal dialysisrelated infections recommendations: 2005 update. Perit Dial Int 2005; 25(2): 107-131.

5. Li PK, Szeto CC, Piraino B, et al. Peritoneal dialysis-related infections recommendations: 2010 update. Perit Dial Int 2010; 30(4): 393-423. http://dx.doi.org/10.3747/pdi.2010.00049

6. Funke G, von Graevenitz A, Clarridge JE 3rd, et al. Clinical microbiology of coryneform bacteria. Clin Microbiol Rev 1997; 10: 125-159.

7. Thirugnanasambathan T, Hawley CM, Badve SV, et al. Repeated peritoneal dialysis-associated peritonitis: a multicenter registry study. Am / Kidney Dis 2012; 59(1): 84-91. http://dx.doi. org/10.1053/j.ajkd.2011.06.018

8. Chiu YL, Wu VC, Wun KD, Hsueh PR. Recurrent peritonitis caused by Corynebacterium amycolatum in a patient undergoing continuous ambulatory peritoneal dialysis. Clin Nephrol. 2005; 63(3): 241-242.

9. Barraclough K, Hawley CM, McDonald SP, et al. Corynebacterium peritonitis in Australian peritoneal dialysis patients: predictors, treatment and outcomes in 82 cases. Nephrol Dial Transplant 2009; 24(12): 3834-3839. http:// dx.doi.org/10.1093/ndt/gfp322 